\title{
Sistem Autodocking Mobile Robot Berbasis Suara untuk Pengisian Ulang Baterai
}

\author{
Ari Hidayanto dan Muhammad Rivai, Astria Nur Irfansyah \\ Departemen Teknik Elektro, Fakultas Teknologi Elektro, \\ Institut Teknologi Sepuluh Nopember (ITS) 60111 Indonesia \\ e-mail: muhammad_rivai@ee.its.ac.id
}

\begin{abstract}
Abstrak-Siklus kerja autonomous mobile robot dirancang penuh untuk mampu berjalan dan bekerja secara kontinyu dengan lintasan yang sudah ditentukan oleh waypoint Global Positioning System (GPS) tanpa ada campur tangan manusia. Salah satu sistem yang cukup penting pada mobile robot untuk masalah tersebut adalah sistem autodocking yang digunakan ketika baterai dalam level rendah atau akan habis supaya kembali ke power station untuk mengisi ulang baterai. Dalam proses menuju power station diperlukan keakuratan mobile robot agar posisi antara transmitter dengan receiver baterai berada pada jarak transfer Wireless Power Transmision (WPT). Penelitian ini mengimplementasikan mobile robot yang dirancang menggunakan Arduino Mega 2560 sebagai kontrol utama sistem, GPS Ublox Neo M8N, modul kompas HMC5883L, modul mikrofon kondenser, modul HC-SR04, motor driver L298N dengan 4 buah motor DC, dan LCD. Sedangkan untuk sumber suara menggunakan speaker Polytron Muze (PSP B1) dengan suara sonar yang memiliki rentang frekuensi $900 \mathrm{~Hz}$ hingga $1100 \mathrm{~Hz}$. Modul mikrofon ditempatkan pada sisi kanan dan kiri mobile robot dengan metode mencari arah sumber suara pada WPT berdasarkan different level intensity. Hasil pengujian penelitian ini menunjukkan mobile robot yang dirancang memiliki kemampuan menuju titik waypoint dengan error jarak posisi mencapai 6 meter. Penggunaan corong pengarah pada sensor suara memiliki efektifitas sudut directivity $90^{\circ}$ dan $-\mathbf{9 0}^{\circ}$ membuat sensor suara menjadi lebih sensitif. Sedangkan mobile robot dapat mendeteksi suara dan menuju ke sumber suara dengan efektifitas jarak kurang dari $100 \mathrm{~cm}$ yang memiliki waktu tempuh kurang dari 60 detik.
\end{abstract}

Kata Kunci-Autodocking, Mobile Robot, Power Station, Sensor Suara.

\section{PENDAHULUAN}

$\mathrm{D}$ ALAM proses kegiatan eksplorasi hingga produksi minyak dan gas pastinya menghasilkan temuan berbagai senyawa kimia yang belum diketahui secara pasti kadar maupun tingkat keamanannya. Ketika manusia secara langsung mengecek area dan kondisi senyawa kimia tersebut, kemungkinan resiko terkena dampak negatif bagi keamanan dan kesehatan diri seperti sesak nafas hingga kemandulan akan lebih besar.

Sebagai upaya untuk mencegah terjadinya kecelakaan dalam kegiatan eksplorasi dan produksi dalam dunia gas salah satunya dapat menggunakan mobile robot yang akan secara kontinyu memetakkan titik-titik lokasi keberadaan senyawa kimia minyak atau gas. Mobile robot ini akan berjalan secara autonomous dan mandiri dimana robot mampu terus berjalan dan bekerja.

Salah satu sistem yang cukup penting pada mobile robot tersebut adalah sistem autodocking yang digunakan ketika baterai dalam level rendah atau akan habis supaya kembali ke power station untuk mengisi ulang baterai. Metoda yang populer digunakan sebagai penentuan titik kembali untuk autodocking adalah waypoint GPS, namun waypoint GPS memiliki error jarak yang cukup jauh sehingga tidak dapat secara tepat masuk ke dalam docking station. Dalam penelitian ini telah dirancang sistem autodocking dengan kombinasi 2 metode yaitu ketika mobile robot ada di jarak yang jauh akan menggunakan waypoint GPS, kemudian ketika GPS telah sampai pada titik yang dituju, metode jarak dekat dengan sensor suara akan aktif.

Dalam proses menuju power station diperlukan ketepatan posisi mobile robot agar posisi antara transmitter dengan receiver charger baterai sesuai. Maka dari itu pada mobile robot menggunakan sensor audio sebagai telinga dari robot untuk memposisikan secara tepat dan sesuai. Kemampuan mobile robot untuk dapat berjalan menelusuri area dan kembali ke power station (dock) merupakan salah satu sistem otomasi yang sangat dibutuhkan agar robot dapat terus bekerja secara normal.

\section{TEORI PENUNJANG}

\section{A. Mobile Robot}

Mobile robot adalah robot yang memiliki mekanisme penggerak berupa roda (wheel) dan atau kaki (leg), untuk dapat berpindah tempat dari suatu tempat ke tempat yang lain. Mobile robot digunakan secara luas sebagai aktuator dalam berbagai bidang aplikasi dengan dilengkapi sensor untuk mengendalikan pergerakan robot tersebut[1].

Mobile robot diklasifikasikan menjadi dua yaitu menurut lingkungan tempat robot tersebut bekerja dan alat yang digunakan untuk bergerak. Berdasarkan lingkungan tempat robot tersebut bekerja, mobile robot terbagi menjadi empat macam yaitu land robot, Unmanned Aerial Vehicle (UAV), Autonomous Underwater Vehicles (AUVs), dan robot yang bekerja pada lingkungan kutub, dimana robot tersebut berkerja pada kondisi permukaan tanah yang dilapisi es (polar robots).

Sedangkan berdasarkan alat yang digunakan untuk bergerak, robot mobil terbagi menjadi robot berlengan atau berkaki dan robot beroda. Untuk robot berlengan, lengan atau kaki berbentuk menyerupai manusia (android) ataupun hewan, robot beroda atau Wheeled Mobile Robot (WMR).

\section{B. Autodocking System}

Salah satu contoh penggunaan mobile robot yaitu robot navigasi yang dapat difungsikan dalam berbagai hal, antara lain memetakan lokasi dan memonitoring kondisi lingkungan. Mobile robot navigasi ini memiliki komponen utama sebagai penentuan titik geraknya robot yaitu Global Positioning System (GPS) sehingga navigasi mobile robot dapat dirancang secara autonomous yang terus berjalan dan bekerja tanpa ada campur tangan manusia, kecuali robot 
mengalami kerusakan. Dalam siklus kerjanya tersebut, kebutuhan power suplai dari baterai agar tetap dalam level yang normal merupakan hal penting. Sistem autodocking merupakan sistem kemandirian robot agar mampu kembali ke docking station atau power station sehingga dapat mengisi ulang baterai.

Integrasi antara sensor pada mobile robot dengan docking station akan sangat dibutuhkan agar robot mampu kembali ke posisi yang tepat dan memposisikan badan robot dengan sesuai. Dibutuhkan desain docking station yang memiliki pemancar suara dengan frekuensi tertentu agar sensor suara dapat mendeteksinya. Penempatan sumber suara itu juga harus ditempatkan pada posisi yang sesuai dengan transmitter pada power station dan receiver pada mobile robot sehingga pengisian ulang baterai dapat optimal.

\section{Navigasi Waypoint}

Navigasi merupakan teknik untuk membaca kedudukan (posisi) dan arah benda terhadap kondisi di sekitarnya. Pada umumnya menemukan keduduan dan posisi dari benda dapat dilakukan dengan melihat beberapa penanda dengan sensor[2]. Metode umum untuk mewujudkan navigasi otomatis dapat melalui navigasi visual, model peta navigasi dan navigasi waypoint[3]. Metode inilah yang akan digunakan sebagai kemampuan kemampuan robot untuk berjalan secara otomatis menuju suatu titik tujuan pada bidang $\mathrm{x}-\mathrm{y}$ tanpa bantuan manusia yang juga disebut sebagai autonavigation robot.

Koordinat yang digunakan dapat bervariasi tergantung pada aplikasi. Misalnya yang berkenan dengan navigasi pada permukaan bumi, koordinat ini dapat mencakup lattitude dan longitude. Waypoint yang ditempatkan di atas permukaan bumi, biasanya didefinisikan dalam dua dimensi (lattitude dan longitude). Pada navigasi waypoint dalam dua dimensi, penentuan posisi target terhadap suatu objek atau benda dapat dilihat pada gambar 1 . Jarak antara posisi benda dengan target dapat dihitung dengan persamaan (1).

$$
R_{\text {target }}=\sqrt{X_{t \text { arget }}^{2}+Y_{\text {target }}^{2}}
$$

Variable Xtarget dan Ytarget merupakan koordinat lattitude dan longitude yang akan dituju. Sehingga arah yang harus dituju oleh benda $(\omega)$ dapat dihitung dengan persamaan (2).

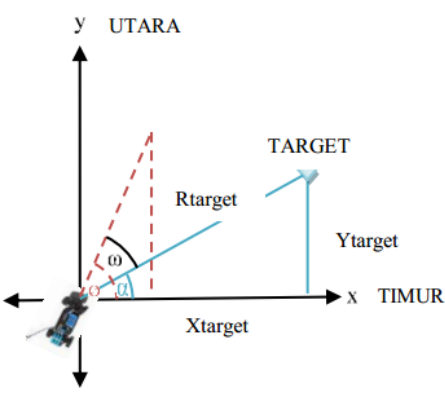

Gambar 1. Penggambaran titik target terhadap objek[4].

$$
\alpha=\tan ^{-1}\left(\frac{Y t \arg e t}{X t \arg e t}\right)
$$$$
\omega=\alpha-\theta
$$

Sudut $\alpha$ pada persamaan (3) merupakan sudut yang dibentuk setelah menentukan titik target, dan sudut $\theta$ merupakan sudut yang didapat dari kompas.

\section{Electret Microphone}

Microphone (mikrofon) adalah suatu alat atau komponen elektronika yang dapat mengubah atau mengkonversikan energi akustik (gelombang suara) ke energi listrik (sinyal audio). Microphone merupakan keluarga transduser yang berfungsi sebagai komponen atau alat pengubah satu bentuk energi ke bentuk energi lainnya. Setiap jenis Mikrofon memiliki cara yang berbeda dalam mengubah bentuk energinya, tetapi mereka semua memiliki persamaan yaitu semua jenis microphone memiliki suatu bagian utama yang disebut dengan diafragma. Jenis diafragma yang dipakai sangat beragam, salah satunya adalah material elektret atau yang sering disebut electret microphone.

Electret merupakan kerabat dekat bahan piezoelektrik sehingga bahan electret dikembangkan dengan metode piezoelektrik. Electret adalah bahan dielektrik kristal terpolarisasi elektrik permanen dimana merupakan transduser elektrostatik yang terdiri dari electret metal dan backplate yang dipisahkan dari diafragma oleh celah udara dengan struktur seperti gambar 2.

Metallization bagian atas dan backplate logam dihubungkan melalui resistor $\mathrm{R}$ dengan $\mathrm{V}$ yang melaluinya, dimana ia dapat diamplifikasi dan digunakan sebagai sinyal output. Karena electret adalah dielektrik yang terpolarisasi secara permanen, kerapatan muatan $\sigma 1$ pada permukaannya konstan dan menetapkan medan listrik $\varepsilon 1$ di celah udara. Bila gelombang akustik menempel pada diafragma, yang terakhir membelok ke bawah, mengurangi ketebalan celah udara s1 untuk nilai s. Pada kondisi sirkuit terbuka, amplitudo bagian variabel dari tegangan keluaran dapat dicari dengan persamaan (4).

$$
V=\frac{s \Delta s}{\varepsilon_{0}\left(s+\varepsilon s_{1}\right)}
$$

Mikrofon dengan diafragma electret memiliki fitur yang lebih sering digunakan daripada jenis mikrofon lainnya. Keunggulan yang ditonjolkan diantaranya rentang frekuensinya sangat lebar mulai dari $10^{-3} \mathrm{~Hz}$ hingga ratusan megahertz.

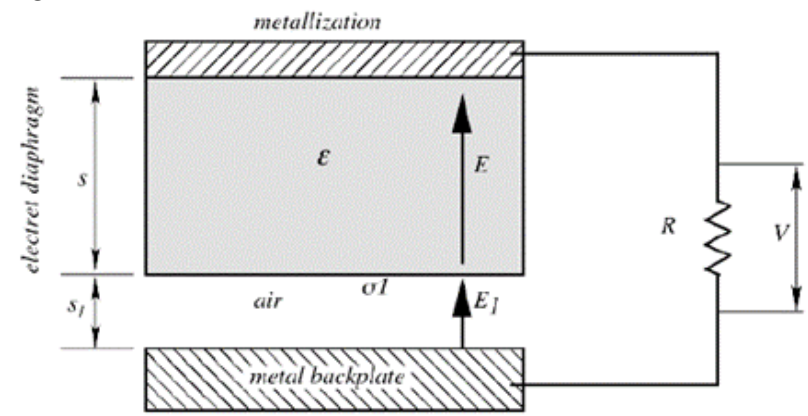

Gambar 2. Struktur umum diafragma electret microphone[5]

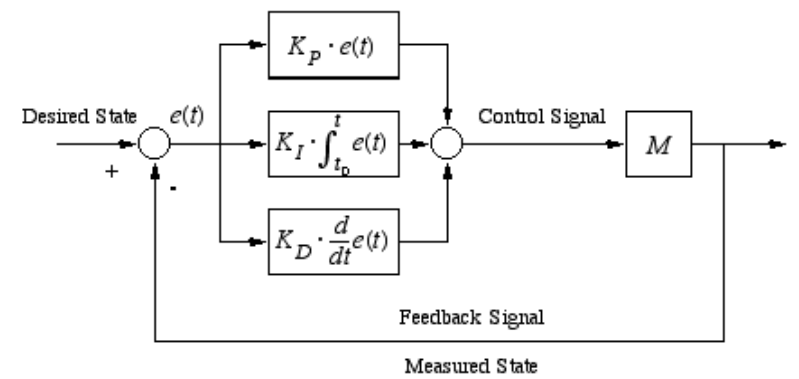

Gambar 3. Kendali proporsional integral derivatif[6].

Mereka juga menampilkan respons frekuensi datar (dalam $\pm 1 \mathrm{~dB}$ ), distorsi harmonis rendah, sensitivitas getaran rendah, 
respon impuls yang baik, dan ketidakpekaan terhadap medan magnet. Sensitivitas mikrofon electret berada dalam kisaran beberapa milimeter per microbar[5].

\section{E. Kendali Proporsional Integral Derivatif}

Kendali proporsional integral derivatif adalah suatu sistem kendali yang merupakan gabungan dari kendali proporsional, kendali integral dan kendali derivatif dimana kendali proporsinal akan menghasilkan keluaran kendali yang sebanding dengan nilai eror sehingga diperoleh nilai yang steady state[6]. Sedangkan kendali integral berfungsi untuk meminimalisir nilai error steady state terhadap setpoint. Untuk mengurangi osilasi atau overshoot respon maka ditambahkan kendali derivatif yang merupakan fungsi derivatif dari nilai error dikalikan dengan konstanta derivatif sehingga kendali PID ditunjukkan pada persamaan (5), dan diagram bloknya ditunjukkan pada gambar 3.

$$
u(t)=P(t)=K_{p} e(t)+K_{i} \int_{0}^{t} e(\tau) d \tau+K_{d} \frac{d e(\tau)}{d \tau}
$$

\section{F. Metode Penentuan Arah Sumber Suara}

Penelitian pada sistem lokalisasi suara pada manusia sudah dilakukan selama beberapa dekade dan mekanisme dari lokalisasi sumber suara pada manusia sudah diketahui. Dari penelitian itu terlihat bahwa manusia menggunakan beberapa petunjuk untuk mendapatkan lokasi sumber suara yaitu membedakan level atau intensitas suara dan waktu sampai suara dari sumber ke telinga[7]. Sudah banyak dilakukan penelitian mengenai pengenalan lokasi sumber suara menggunakan beberapa array mikrofon yang memakai lebih dari 3 buah mikrofon, akan tetapi penelitian sistem pengenalan lokasi sumber suara yang menggunakan 2 buah mikrofon seperti pendengaran manusia masih jarang dilakukan[8].

Pada penelitian ini telah dirancang suatu sistem untuk membedakan intensitas dan level suara dengan cara menangkap suara atau bunyi dari sumber dengan 2 buah mikrofon. Dimana intensitas suara adalah energi yang dibawa oleh gelombang bunyi per satuan waktu melalui perubahan setiap satuan luas. Intensitas dapat dibandingkan dengan amplitudo gelombang suara \& memiliki satuan SI Watt/ meter $^{2}\left(\mathrm{~W} / \mathrm{m}^{2}\right)$ seperti yang ditunjukkan persamaan (6).

$$
I=\frac{P}{A}
$$

Diketahui bahwa telinga manusia sensitif dengan berbagai intensitas suara. Jadi skala intensitas logaritmik digunakan, yang didefinisikan oleh persamaan (7).

$$
\beta=(10 d B) \log I 0
$$

\section{PERANCANGAN SISTEM}

TABEL 1.

DAFTAR WAYPOINT

\begin{tabular}{ccc}
\hline \hline No. WP. & LATTITUDE & Longitude \\
\hline 1 & -7.285123 & 112.796288 \\
2 & -7.285123 & 112.796288 \\
3 & -7.285088 & 112.795898 \\
4 & -7.285088 & 112.795898 \\
\hline \hline
\end{tabular}

\section{A. Arsitektur Sistem}

Gambar 4 merupakan penyederhanaan dari kombinasi sistem Autonomous Navigation Robot menggunakan GPS dengan sistem sound localization sebagai penelitian ini.
Perencanaan sistem ini bertujuan agar robot dapat bekerja sesuai dengan perencanaan. Yaitu dapat berjalan sesuai arah dari koordinat yang diberikan secara otomatis, mendeteksi sumber suara berada, dan menuju ke arah sumber suara tersebut.

Aplikasi dari adanya sumber suara diharapkan mampu memperbaiki toleransi dari kesalahan pembacaan koordinat GPS yang diberikan. Hal tersebut berpengaruh kepada optimalisasi pengisian baterai yang dilakukan secara wireless, dimana radiasi pengisian dapat terjadi pada jarak tertentu dari area power station.

\section{B. Perancangan Perangkat Keras}

Berdasarkan gambar 4 dapat diketahui bahwa komponen penyusun mobile robot terdiri dari power supply baterai LiPo 2200 mAh, GPS Ublox Neo M8N, kompas digital HMC5883L, dan 2 buah modul sensor suara sebagai inputannya. Mikrokontroler Arduino Mega 2560 digunakan sebagai otak sistem dengan keluaran berupa tampilan LCD 16x4 dan gerak 4 buah motor DC yang diparalel menjadi 2 buah gerakan dengan pengendali motor driver L298N.

\section{Perancangan Perangkat Lunak}

Titik koordinat waypoint didapatkan dari hasil pemetaan koordinat pada sebuah aplikasi PC seperti Google Map. Kemudian memasukkan data lattitude dan longitude yang diperoleh ke dalam program Arduino sebagai instruksi koordinat waypoint tujuan. Dengan menggunakan formula phytagoras, akan didapatkan jarak antara 2 titik. Di mana titik A dapat direpresentasikan sebagai titik asal, dan titik B sebagai titik tujuan. Jarak titik A ke B dapat dicari menggunakan formula $\sqrt{\Delta x^{2}+\Delta y^{2}}$ di mana $\Delta \mathrm{x}$ adalah selisih antara lintang sekarang dikurangi lintang tujuan, dan $\Delta y$ adalah selisih antara bujur sekarang dikurangi bujur tujuan. Jika sudah diketahui jarak, maka dapat disusun algoritma waypoint. Jika sudah diketahui jarak, maka dapat disusun algoritma waypoint seperti yang ditunjukkan gambar 5 .

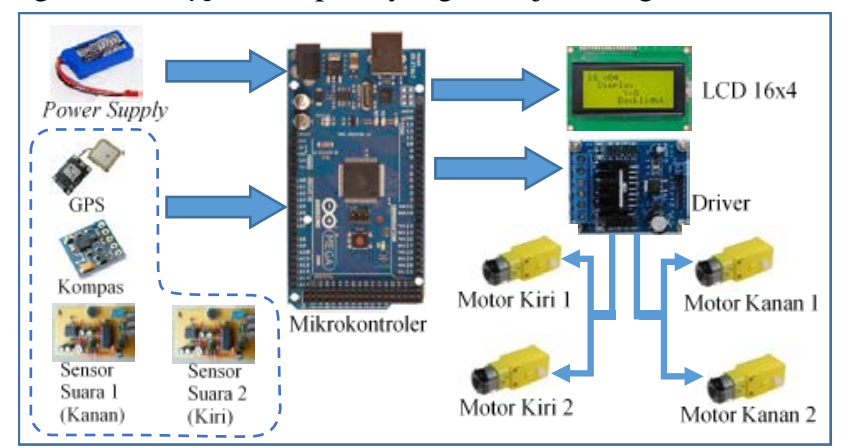

Gambar 4. Diagram perancangan sistem perangkat peras[9].

Pada diagram alir gambar 5, ketika robot mulai, pertama kali menginisialisasi data masukan berupa koordinat waypoint yang telah diset. Setelah task dari tiap tugas aktif, maka program akan mulai membaca nilai sensor GPS, dan kompas. Task navigasi ke waypoint mengukur jarak dan arah robot terhadap heading dan tujuan. Dalam urutan tersebut, terdapat kondisi pemeriksaan untuk menghentikan segala aktifitas navigasi waypoint. Jika jarak mobile robot dengan waypoint kurang dari 3 meter maka metode pencarian suara akan mulai aktif. 


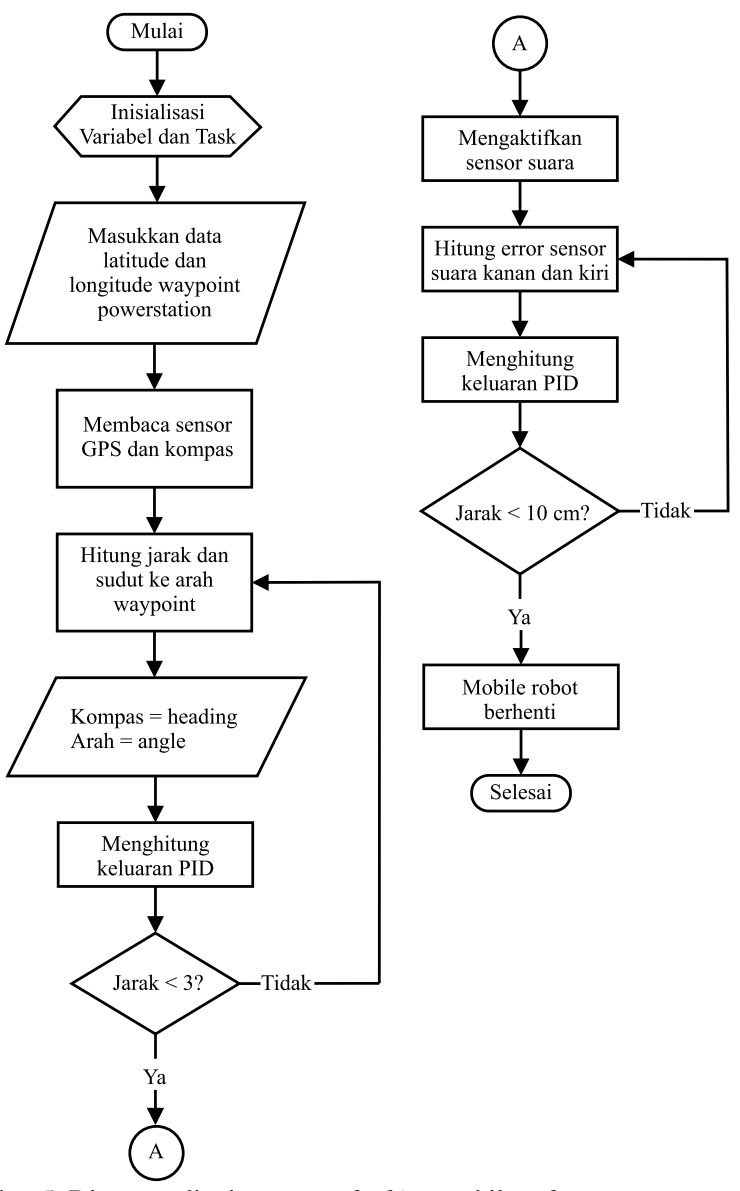

Gambar 5. Diagram alir sistem autodocking mobile robot

Jika nilai sensor suara kanan lebih besar daripada sensor suara kiri maka robot akan bergerak ke kanan, jika nilai sensor suara kiri lebih besar dari pada sensor suara kanan makan robot akan berbelok ke kiri, dan jika nilai antara sensor kanan dengan sensor kiri sama maka robot bergerak maju. Hal tersebut menjadi acuan untuk mengatur PID pada pergerakan robot dengan berdasarkan sensor suara. Robot akan berhenti ketika telah mencapai nilai maksimal yang telah diinstruksikan dalam program. Jika mobile robot mendeteksi jarak kurang dari $10 \mathrm{~cm}$ maka robot akan berhenti, dimana jarak tersebut merupakan jarak pancar Wireless Point Transmission atau wireless charging.

\section{PENGUJIAN SISTEM}

\section{A. Pengujian Navigasi Waypoint}

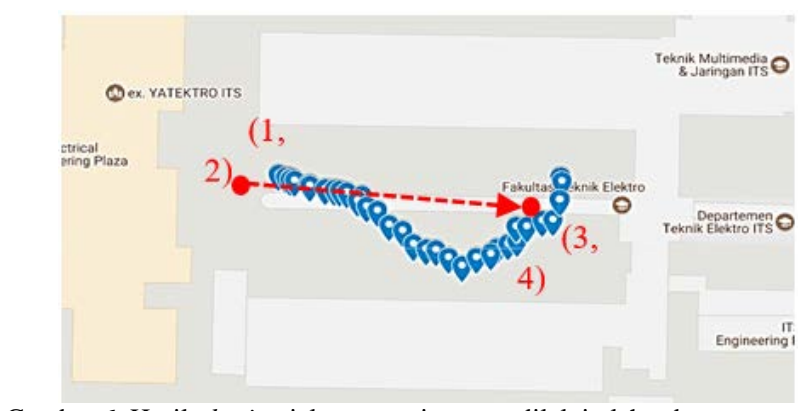

Gambar 6. Hasil plotting jalur waypoint yang dilalui oleh robot

TABEL 2.

Data KoORdinat PeRJALANAN Mobile Robot

\begin{tabular}{cccc}
\hline \hline Lattitude & LONGITUDE & Lattitude & Longitude \\
\hline-7.285123 & 112.796288 & -7.2851673 & 112.7960756 \\
-7.285087 & 112.795907 & -7.2851873 & 112.7960899 \\
-7.285091 & 112.795917 & -7.285194 & 112.7961074 \\
-7.285092 & 112.795925 & -7.2851956 & 112.7961199
\end{tabular}

\begin{tabular}{cccc}
-7.285193 & 112.7962037 & -7.2852066 & 112.7961369 \\
-7.285094 & 112.795923 & -7.2852185 & 112.7961552 \\
-7.285095 & 112.79593 & -7.2852062 & 112.7961749 \\
-7.285101 & 112.795948 & -7.2852009 & 112.7961949 \\
-7.285102 & 112.79595 & -7.2851872 & 112.7962176 \\
-7.285107 & 112.79597 & -7.2851819 & 112.7962295 \\
-7.285108 & 112.795983 & -7.2851619 & 112.7962294 \\
-7.285109 & 112.795981 & -7.2851615 & 112.7962438 \\
-7.285112 & 112.796 & -7.285091 & 112.796289 \\
-7.285117 & 112.796021 & -7.2851532 & 112.796264 \\
-7.285124 & 112.796014 & -7.2851515 & 112.7962786 \\
-7.285133 & 112.796027 & -7.285097 & 112.796291 \\
-7.285139 & 112.796041 & -7.285123 & 112.796288 \\
-7.285159 & 112.796057 & & \\
\hline \hline
\end{tabular}

Pengujian navigasi waypoint dilakukan untuk mengetahui seberapa besar ketepatan robot dalam bernavigasi menuju titik-titik waypoint yang ditentukan. Titik-titik waypoint yang ditunjukkan pada tabel 1 didapat dengan menentukan koordinat yang terlihat pada Google Maps dengan hasil plot koordinat seperti pada gambar 6 yang berwarna merah.

Setelah waypoint dimasukkan, robot dijalankan dan mengirimkan koordinat perjalanan setiap 2 detik. Hasil data pengiriman koordinat ditunjukkan pada tabel 2. Data hasil perjalanan dan data waypoint kemudian di-plot seperti pada gambar 6 untuk menunjukkan jalur yang telah dilalui oleh robot dengan jalur yang seharusnya dilalui. Tanda lokasi biru merupakan garis perjalanan, sedangkan garis merah merupakan garis jalur waypoint. Pada beberapa titik terjadi banyak simpangan antara jalur yang seharusnya dengan jalur yang dilewati oleh robot. Pada titik 1 pergeseran sebesar 1,85 meter, pada titik 3 pergeseran sebesar 3,5 meter. Hal ini dapat dikarenakan simpangan sensor kompas. Kemudian jumlah satelit yang mengunci GPS juga sangat berpengaruh. Semakin banyak jumlah satelit yang mengunci, semakin tinggi keakuratan dari GPS dan juga kondisi cuaca yang kurang baik.

\section{B. Pengujian Directivity Sensor Suara Pada Mobile Robot}

Untuk mengetahui karakteristik kombinasi dari sensor suara yang digunakan pada hardware mobile robot dilakukan pengujian dengan memperhatikan jarak radius dari titik tengah dari mobile robot terhadap speaker dan sudut dari sumber suara. Bunyi atau suara yang digunakan adalah suara sonar kapal dengan rentang frekuensi $900 \mathrm{~Hz}$ hingga $1100 \mathrm{~Hz}$ dengan bentuk sinyal sinus yang terukur pada osiloskop ditunjukkan oleh gambar 7 .

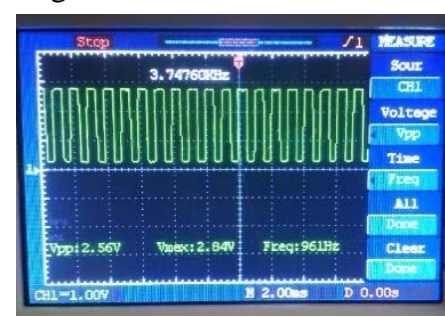

Gambar 7. Bentuk sinyal sumber suara pada osiloskop

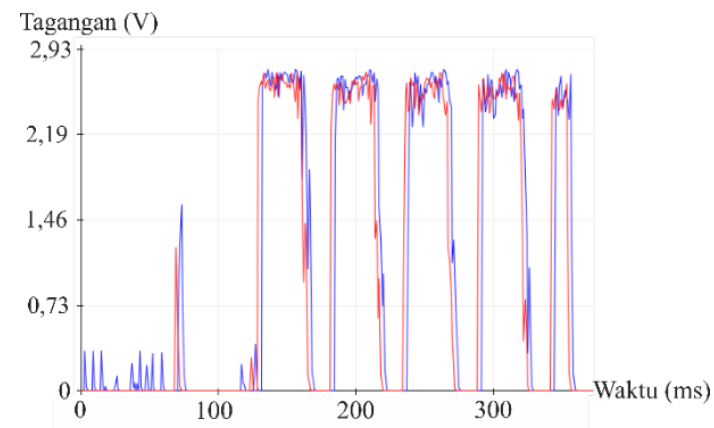

Gambar 8. Bentuk sinyal sumber suara pada serial plotter 
TABEL 3.

DATA PEMBANDINGAN DIRECTIVITY

\begin{tabular}{ccccccccc}
\hline \hline \multirow{2}{*}{ Sudut } & \multirow{2}{*}{ Pengukuran } & \multicolumn{7}{c}{ Jarak (cm) } \\
\cline { 3 - 9 } & & $\mathbf{2 5}$ & $\mathbf{5 0}$ & $\mathbf{7 0}$ & $\mathbf{1 0 0}$ & $\mathbf{1 2 0}$ & $\mathbf{1 5 0}$ & $\mathbf{2 5 0}$ \\
\hline \multirow{2}{*}{$0^{\circ}$} & Level (dB) & 59 & 55 & 53 & 52 & 50 & 49 & 43 \\
& ADC Kanan & 557 & 536 & 523 & 522 & 521 & 518 & 476 \\
\multirow{2}{*}{$45^{\circ}$} & ADC Kiri & 555 & 546 & 546 & 520 & 518 & 515 & 482 \\
& ADC Kanan & 539 & 538 & 519 & 501 & 493 & 486 & 472 \\
$90^{\circ}$ & ADC Kiri & 555 & 550 & 548 & 546 & 539 & 534 & 527 \\
& ADC Kanan & 562 & 542 & 535 & 530 & 524 & 511 & 451 \\
$135^{\circ}$ & ADC Kiri & 569 & 565 & 564 & 562 & 559 & 540 & 502 \\
& ADC Kanan & 546 & 536 & 530 & 528 & 523 & 521 & 488 \\
$180^{\circ}$ & ADC Kiri & 563 & 562 & 560 & 559 & 555 & 551 & 531 \\
& ADC Kanan & 550 & 534 & 520 & 517 & 516 & 511 & 465 \\
$-135^{\circ}$ & ADC Kiri & 551 & 541 & 539 & 516 & 514 & 507 & 469 \\
& ADC Kanan & 567 & 564 & 559 & 557 & 550 & 550 & 528 \\
$-90^{\circ}$ & ADC Kiri & 560 & 557 & 549 & 533 & 528 & 524 & 485 \\
& ADC Kanan & 569 & 568 & 566 & 566 & 560 & 554 & 512 \\
$-45^{\circ}$ & ADC Kiri & 563 & 554 & 553 & 549 & 539 & 532 & 485 \\
& ADC Kanan & 557 & 556 & 556 & 555 & 550 & 549 & 535 \\
& ADC Kiri & 532 & 530 & 530 & 528 & 524 & 520 & 498 \\
\hline \hline
\end{tabular}

Speaker yang digunakan adalah speaker tunggal yang memiliki keunggulan penyebaran yang luas, dan ukuran speaker bervariasi. Speaker tunggal memiliki tingkat penyebaran sesuai ukurannya dan desain frekuensi kerjanya. Tetapi bila diinginkan suara dapat sampai pada jarak dan pendengar yang banyak maka suara satu sumber memerlukan daya yang besar bila dibandingkan output sejumlah speaker secara bersamaan[9]. Pengukuran dilakukan membandingkan nilai pengukuran suara menggunakan sound level meter dengan pembacaan nilai ADC pada serial plotter yang telah dikonversi ke dalam satuan tegangan dengan hasil seperti pada gambar 8. Dalam hal ini sound level meter yang digunakan adalah aplikasi ukur tingkat suara pada ponsel yang diukur dalam satuan $\mathrm{dB}$ dan nilai $\mathrm{ADC} 10$ bit pada Arduino.

Dengan memperhatikan jarak dan sudut dari sumber suara akan dicari directivity yang merupakan ukuran karakteristik arah dari sumber suara berasal. Karakteristik arah sumber suara sangat dipengaruhi oleh permukaan pantulan di dekatnya.

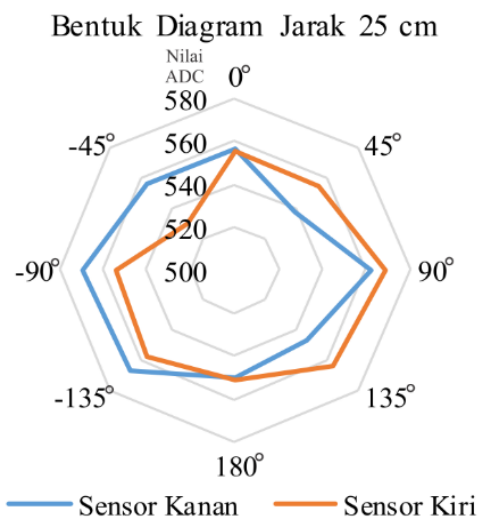

Gambar 9. Bentuk Diagram Radar Directivity Jarak 25 cm

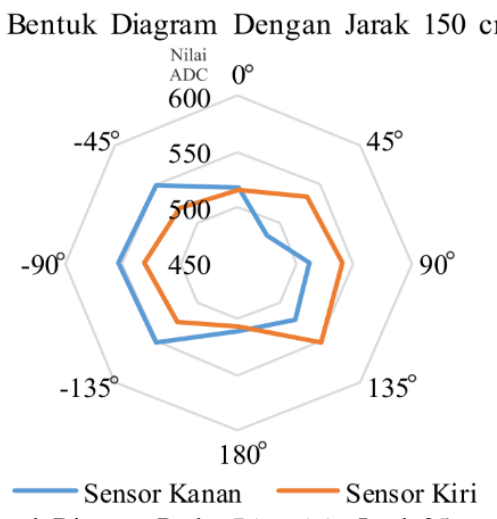

Gambar 10. Bentuk Diagram Radar Directivity Jarak 25 cm
Berdasarkan tabel 3, kemudian akan dibuat menjadi diagram radar seperti gambar 9 dan gambar 10. Dengan melihat dan membandingkan gambar 9 dengan gambar 10 terlihat bahwa sudut pembacaan directivity sumber suara sangat baik pada sudut $90^{\circ}$ untuk sensor suara kanan dan $-90^{\circ}$ untuk sensor suara kiri dengan nilai selalu lebih dari 550 . Hasil tersebut membuktikan bahwa suara sangat efektif dengan arah tegak lurus antara pancaran suara dengan media terima.

\section{Pengujian Tingkat Keberhasilan}

Untuk mengetahui nilai persentase nilai tingkat keberhasilan dilakukan dengan cara menguji mobile robot secara kontinyu dengan jarak dan sudut yang berbeda. Dalam hal ini, jarak yang diujikan dari $25 \mathrm{~cm}$ hingga $250 \mathrm{~cm}$ dengan sudut masih-masing tiap jarak $0^{\circ}$ hingga $-45^{\circ}$ seperti halnya pada pengujian directivity ditunjukkan oleh gambar 11 . Mobile robot akan diuji menuju ke titik lokasi dimana sumber suara berada dengan simulasi transmitter Wireless Power Transmission (WPT) berupa kertas karton pada sumber suara dan simulasi receiver WPT yang juga berupa kertas ditempatkan pada mobile robot ditunjukkan oleh gambar 12 . Hasil pengujian tingkat keberhasilan ini ditunjukkan oleh tabel 4 dengan tanda centang yang berarti berhasil dan tanda strip untuk percobaan yang gagal.

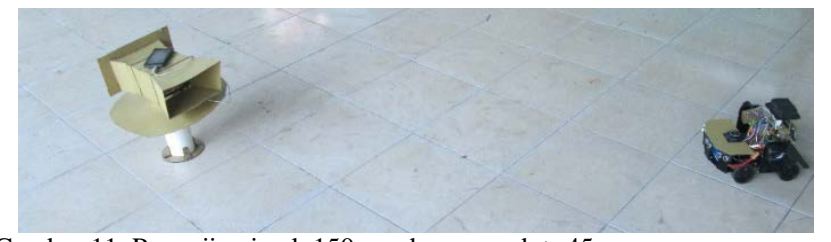

Gambar 11. Pengujian jarak $150 \mathrm{~cm}$ dengan sudut -45

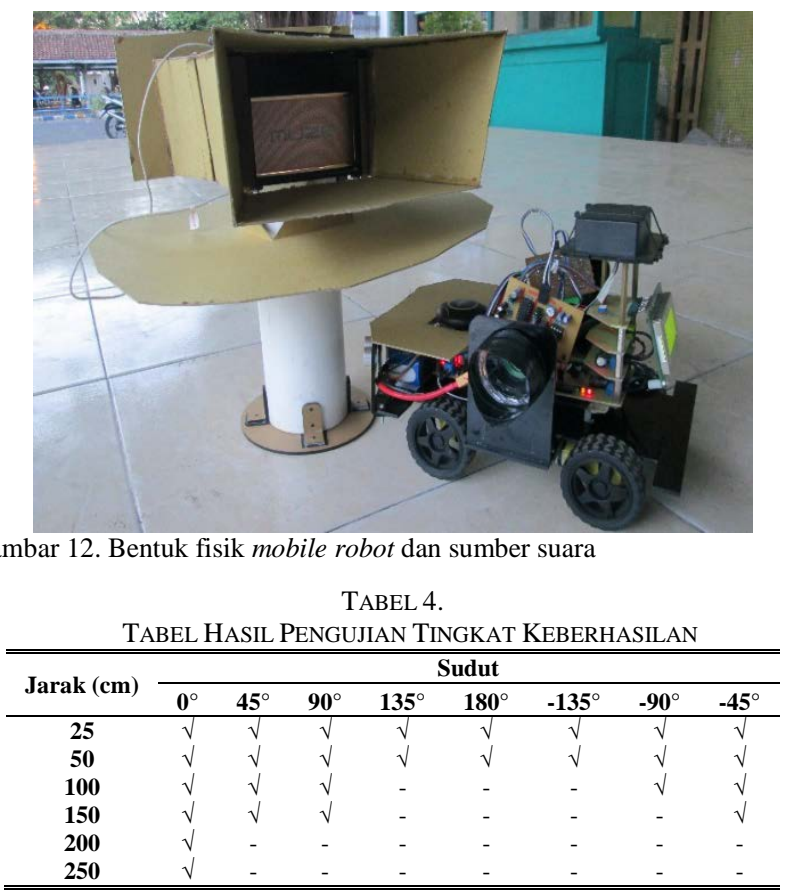

Berdasarkan data dari tabel 4 terlihat bahwa sistem autodocking mobile robot berbasis suara yang telah dibuat cenderung berhasil menuju ke power station dengan tingkat keberhasilan sebesar 56,25\%. Faktor yang mempengaruhi keberhasilan dari sistem autodocking berbasis suara ini antara lain adalah kondisi lingkungan dimana tidak banyak media pantul, tingkat kebisingan (noise), kondisi cuaca dimana cuaca yang cerah dan tidak berangin akan menghasilkan hasil yang baik karena angin dan temperature sangat 
mempengaruhi kecepatan rambat dari sumber suara menuju ke mobile robot. Pada percobaan ini dilakukan pada kondisi di luar ruangan dengan cuaca cerah namun angin bertiup cukup kencang yang membuat sebagian suara terbawa angin sehingga suara yang terdengar mobile robot tidak terlalu jelas.

Hasil akhir yang diharapkan dari tabel 4 tingkat keberhasilan yang disajikan dalam sebuah nilai persentase dapat dicari dengan persamaan 8 .

$$
\begin{aligned}
& S R=\frac{\text { data_berhasil }}{\text { data_keseluruhan }} \times 100 \% \\
& S R=\frac{27}{48} \times 100 \% \\
& S R=56,25 \%
\end{aligned}
$$

\section{KESIMPULAN}

Pada penelitian ini diperoleh mobile robot dengan sistem autodocking berbasis suara menggunakan metode Different Level Intensity yang memiliki kemampuan menuju titik waypoint dengan error jarak posisi mencapai 6 meter. Hal tersebut dibuktikan dari hasil pengujian navigasi waypoint GPS yang tidak tegak lurus dalam menuju titik waypoint. Penerapan penggunaan corong pengarah pada sensor suara memiliki efektifitas sudut directivity $90^{\circ}$ dan $-90^{\circ}$ sangat membantu mengurangi kerugian pembacaan level sumber suara yang memiliki suara audio dengan rentang frekuensi $900 \mathrm{~Hz}$ - $1100 \mathrm{~Hz}$ sehingga sensor suara menjadi lebih sensitif. Sedangkan mobile robot dapat mendeteksi suara dan menuju ke sumber suara dengan tingkat keberhasilan 56,25\%.

\section{DAFTAR PUSTAKA}

[1] D. I. Pratiwi, "Rancang bangun deteksi jalur pipa terpendam menggunakan mobile robot dengan metal detector," Institut Teknologi Sepuluh Nopember, Surabaya, 2017.

[2] D. Reyes, G. Millan, R. Osorio-Corparan, and G. Lefranc, "Mobile robot navigation assisted by GPS,” IEEE Lat. Am. Trans., vol. 13, no. 6, pp. 1915-1920, Jun. 2015.

[3] S. Rady, A. A. Kandil, and E. Badreddin, "A hybrid localization approach for UAV in GPS denied areas," in 2011 IEEE/SICE International Symposium on System Integration (SII), 2011, pp. 1269-1274.

[4] R. Watiasih, M. Rivai, R. A. Wibowo, and O. Penangsang, "Path planning mobile robot using waypoint for gas level mapping,” in 2017 International Seminar on Intelligent Technology and Its Applications (ISITIA), 2017, pp. 244-249.

[5] J. Fraden, Handbook of modern sensors: physics, designs, and applications, 3. ed., [N. New York, NY: AIP Press, Springer, 2004.

[6] K. Ogata, Teknik kontrol automatik (sistem pengaturan) Jilid 2. Jakarta: Erlangga, 1993.

[7] P. A. A. Adiputra, "Swarm robot menggunakan sistem koordinasi suara untuk mencari sumber gas," Institut Teknologi Sepuluh Nopember, Surabaya, 2017.

[8] F. Budiman, M. A. Nursyeha, M. Rivai, and S. Suwito, "Pengenalan suara burung menggunakan mel frequency cepstrum coefficient dan jaringan syaraf tiruan pada sistem pengusir hama burung,” J. Nas. Tek. Elektro, vol. 5, no. 1, pp. 64-72, Mar. 2016.

[9] O. B. Baskhoro, M. Rivai, and F. Budiman, "Pengarah suara pada sistem audio berdasarkan beda phasa menggunakan FPGA,” J. Tek. ITS, vol. 7, no. 1, pp. 92-97, Mar. 2018. 